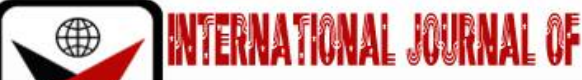

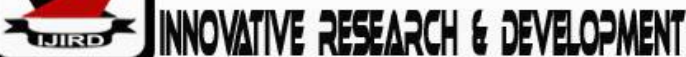

ISSN 2278-0211 (Online)

\section{Effect of Communication Gaps in the Achievement of Organizational Objectives in Adamawa State University, Mubi, Nigeria}

\author{
Mohammed Nasiru \\ M.Sc Student, Department of Business Administration, \\ Adamawa State University, Mubi-Nigeria \\ Kojoli Abubakar Hammawa \\ Graduate Assistant, Department of Business Administration, \\ Adamawa State University, Mubi-Nigeria
}

\begin{abstract}
:
The research study on the impact of communication gap in the achievement of organizational objectives identified how lecturers experience communication gaps through lack of communication skill, having different perceptions, difference in status, distrust, individual emotions, poor listening skill, gender differences, cultural differences and technological jargon. The main purpose of the study is to examine the impact of communication gaps in the achievement of Organizational Objectives; a Case Study of Adamawa State University, Mubi. The study adopted descriptive research design. The total population of the study is eight hundred and twenty-four (824) which comprises of two hundred and thirty-two Academic Staff (232) and five hundred and ninety-two (592) non-academic Staff of different carders. Therefore, the sample size for this study is 269 arrived at using Yemani Yaro formula (1964). The instrument used for collecting data from the respondents is the questionnaire, and the data gathered from the respondent was analyzed using percentage analysis. The result shows that there is significant and positive relationship between variables of the study $(r=0.857, P \leq 0.05)$. Also, it was discovered that poor directives by management causes confusion among employees, communication gap can also influence reduction in information flow between management and subordinate staff, the information provided by the university management are not enough. Also, there is always opposition when opinion of all concerned are not sought in the management meeting before any decision taken. The study therefore, recommends that the management of ADSU Mubi should make clear communication in order to make directive as easier as possible to employees in order to avoid confusion among employees in discharging their duties, there is also need for good flow of information between the management and their subordinates in the institution, it also good for the management to put in cognizance the interest of the organization as well as all staff as a whole in every decision making in the institution.
\end{abstract}

Keywords: Achievement, communication, effect, gaps and organizational

\section{Introduction}

Communication is a means of bringing about change. It is the mainstream of any organization growth. There is need form interaction and understanding of management-employee relations this will bring about increased performance of all parties involved in the communication process or chain. Communication has been widely accepted by scholars and academics as the livelihood of an organization, because communication is needed for exchanging information, exchanging opinions, making plans and proposals, reaching agreement, executing decisions, sending and fulfilling orders and conducting sales (Blalock, 2005; Alyssa, 2006; Kotler, 2006). When communication stops, organized activity ceases to exist, and individual uncoordinated activities return in an organization. So, communication in an organization is as vital as the blood of life.

According to Banihashemi (2011), communication as a medium, a means to performance ends, or as constitutive, as the end in itself. Communication is a process of transmitting information from one person to another. According to Stephen (2011), communication is a critical factor in directing and mobilizing the workforce towards the accomplishment of the organizational goals or objectives. By creating understanding, it enhances co-operation and promote effective performance. According to Williams (2007) smart managers understand that the end effective, straight forward communication between managers and employees is essential for success.

Communication is essential to effective team performance and communications for any organization is like blood flow in the human body. Therefore, any organization that understands the importance of communication uses it in their organizational environment. Since, it ensures coordination of factors of production and most importantly material and human elements of organization as an efficient network of change and advancement (Mckinney, Barker, Smith\& Davis, 
2004). According to Snavely (2001) as cited by Robins (2006), communication process is initialed through the following means the sender-encoding-the message-the channel- decoding-the receiver- noise and feedback. It is estimated that managers spend over $80 \%$ of their day communicating with others. Since most of the basic management processplanning, organizing, leading and controlling - cannot be performed without effective communication.

Importantly, the relevance of communication keeps advancing as the world becomes a Global village. The need to become visible to the world has made many organizations to embrace new technology that would increase organizational performance. There are also many issues affecting communication ranging from difference in sex, role of silence, inference of government and cross- cultural inference. Organizational communication research has mainly been conducted both in the business management field and in the communication field; however, researchers in the public administration field have provided little knowledge about organizational communication and its roles and effects (Eunju, 2009).

Conclusively, in all human organization, the art of communication cannot be overemphasized; it is the means by which people interact and work with one another. Just like blood stream in people, communication represents the bloodstream of organization. This means that nothing can be achieved in an organization without effective communication. Communication skills are important in all human endavours, including business. Even though communication skills are so important to success in the workplace, there are many individuals who find that there is a limit to their communication skills and that they seen to have reached a stumbling block in their progress. They may sometimes struggle to convey their thoughts and ideals in an accurate manner, making it difficult to reach their full potential as a communicator, a manager, and a leader of others.

\section{Statement of the Problem}

Effective communication is an important ingredient within the school management. Whether planning and organizing or leading and monitoring, school administrators communicate with and through other people. This implies that every person's communication skills affect both personal and organizational effectiveness (Brun and Summers, 2010). It seems reasonable to conclude that one of the most inhibiting forces to organizational effectiveness is a lack of effective communication (Lutgen-Sandvik, 2010). Thus, establishing communication should be first task of the staff. Eresimadu (2003) asserts that 'no business or activity can take place in absence of communication'. University activities cannot take place in the absence of communication; it is the root of interaction. It makes the transmission of cumulative knowledge possible. It promotes the transmissions of information, ideas and thoughts. Unfortunately, despite the enormous importance of communication, it is observed that a gap in communication exist in the management of public university in Nigeria.

The problem lecturers experience in communication that led to the communication gaps today include: lack of communication skill, having different perceptions, difference in status, distrust, individual emotions, poor listening skill, gender differences, cultural differences and technological jargon. Other problems are misinterpretation of the message, bad work relationship and lack of knowledge. Unfortunately, no effort is being made to minimize these problems of communication that lecturers in university experience. The implication of these, if not addressed, is that it will bring about school unconnectedness and dysfunctional system which will lead to failure on the part of the school management. The unique nature of communication process requires that lectures and management should critically observe the communication flows which are, downward, upward, and horizontally flow of communication for effective communication. A lot of schools have conducted seminars and conferences on the importance and impact of communication in an organization so as to promote improved organizational objective in the institutions. It is evident that communication gaps still thrive in most of these institutions. Therefore, this study tends to bridge this gap by investigating into the causes, implication and strategy adopt in managing communication gaps towards the achievement of organizational objective using Adamawa State University, as case study.

Some research questions are formulated to serve as guide to the study:

- What are the causes of lack of effective communication in achievement of organizational objective in Adamawa State University, Mubi?

- What are the implications of transmission of information in achievement of organizational objective in Adamawa State University, Mubi?

- What are the strategies to be adopted to minimize lack of communication skills in achievement of organizational objective in Adamawa State University, Mubi?

\subsection{Research Hypothesis}

- $\mathrm{H}_{0}$ : Communication gaps do not have any significant effect on the achievement of organizational objective in Adamawa State University, Mubi.

\subsection{Conceptual Clarification}

\subsubsection{Concept of Communication}

Draft (2000) defines communication as 'the process by which information is exchanged and understood by two or more people usually with the intention to motivate on influence behavior'. Communication refers to the exchange of information between a sender (source) and a receiver (destination) so that it is received, understood and leads to action (Obamiro, 2008). Folarin (2003) defines communication as 'any means by which a thought is transferred from one person to another'. Communication is the process by which any person or a group shares and impacts information with/to another person (or group) so that both people (or groups) clearly understood one another (Soola, 2000). Ugbojah (2001) 
defines communication as 'the process which involves all acts of transmitting messages to channels which link people to the languages and symbolic which are used to transmit such messages. It is also the means by which such messages are received and stored. It includes the rules, customs and conventions which define and regulate human relationship and events'. In its simplest form, however, communication is the transmission of a message from a source to a receiver or the process of creating shared meaning (Baran, 2004).

\subsubsection{Causes of Communication Gaps}

Despite the above numerous advantages of effective communication business all over the world today is very challenging. To stay profitable in the highly challenging and competitive global market economy, all factors of production, i.e. men, machine, method, market, money and materials, should be wisely managed. Physical barriers, linguistic barriers, cultural barriers, lack of honesty, unconscious message distortion, conscious message distortion, poor feedback, work pressure, poor role clarity, poor coordination, poor communication management, poor project management skills, ineffective communication, poor shareholders identification, unclear communication channels, unclear responsibilities, unclear objectives, dissatisfied and unmotivated employees, difference in experience, inexperienced stakeholders, interaction between different professions, different levels of education, greed over project control, lack of training, lack of knowledge, multi organizational interactions, poor communication platform, deficient support to use communication technologies and technology malfunctions (Emuze \& James 2013; Cheng, Dainty \& Moore, 2005).

Among the factors of production, the human resource constitutes the biggest challenge because unlike other inputs, employee management demands skilful handling of thoughts, feelings and emotions to secure highest productivity. Organisational communication plays an important role in this challenge. Inability of a heads or Managers of any organization to coordinate a perfect and smooth flow of communication interaction among employee and outside business environment may likely create and facilitate low productivity with high degree of workers boring and disarray. However, people understand and interpret messages differently. In communication, there are many unwanted interferences that can distort a message and remain always a potential threat to effective communication, because it can interfere with the accuracy of a message being communicated (Koontz 2001).

Organizations in Nigeria have been faced with an array of problems that seem to be an impediment to the growth of any organization such as, mismanagement of funds and resources, poor leadership skills, low level of real income, and poor infrastructural facilities to mention but a few.

\subsection{Implication of Communication Gap in Organizational Objectives}

Communication is deemed ineffective when there is poor listenership, no clarity in speech, bad timing of sharing information, use of jargons, making sarcastic statement or using careless words, attaching emotions to speeches, adopting poor non-verbal communication and portraying deceitful thoughts in communication. Ineffective interaction becomes a blockade to organizational success (Miller, 2009). In an organization, ineffective communication results when managers at the departmental level fails to interact frequently with their workforces. Lack or absence of the 7 indicators aforementioned (Clarity, consideration, courtesy, correctness, completion, concreteness and conciseness) also leads to breakdowns in communication systems (Miller, 2009).

Many at times, wrong perception also hampers communication, which is, the employees might perceive the message in different meaning which was not intended by the manager. Meaning that, there can be a problem in encoding and decoding of message as already stated earlier. Congested organizational structure can also result in communication breakdowns (Cheryl, 2013). When there are complexities in the organizational structure and the number of hierarchical levels in an organization, the chances of loss or misinterpretation of messages becomes greater (Richmond \& McCroskey, 2009). Grapevines as a form of informal channel in communication tend to develop in such an organization thereby obstructing effective communication. In absence of healthy open-door policy, communication may be misunderstood. Poor listening (for instance when the receiver is not focused to what the sender of message is saying) also leads to ineffective communication (Miller, 2006). Referring to previous studies, emotions like anger and stress may also lead to communication breakdown as messages may be interpreted in wrong manner when a person is angry and frustrated than when he is relaxed. Sometimes, the messages are not carefully planned (For example, the medium of transmission of message and the time of message delivery are not chosen rightfully). This again makes communication ineffective. Linguistic differences are a great obstacle in effective communication. This is perhaps due to ambiguity of language. Managers should try to overcome all the causes for communication breakdowns so as to ensure organizational success. According to Chudi -0ji (2013), In spite of the laudable roles of effective communication in improving organizational performances, it is regrettable that some faculties pay lip service to the maintenance of effective communication systems. Change is a gradual and continuous process, giving room for inputs and adjustments. The new innovations, e-classroom, ICT awareness and appraisal methods are good in itself but the medium and level of communication is problematic.

\subsection{Strategies to Minimize Communication Gaps}

Today, effectively communicating your story of change faces increasing challenges - from generational dynamics to information overload in all aspects of our lives. And these challenges provoke those responsible for internal communications to rethink the 'who, when, and how' of communicating information. In spite of these challenges, we've discovered through work with a number of nonprofit clients that there are five key actions organizations can take to ensure internal communications helps advance buy-in for change: 


\subsubsection{Share the Responsibility}

When it comes to communicating change, more often than not the responsibility falls on the shoulders of a group of individuals specifically tasked with managing communications. While many assume that the primary responsibility should lie with this group of people, they are not the necessarily the right—or only-people to take the lead on communicating change. The truth is that when you unpack the work of the internal communications function, you discover that there are bits and pieces of it everywhere. Communicating change should be a shared responsibility, and in order to figure out who should be doing what, you need to understand where the work is being performed across the organization. Once you have that 'systems view' of internal communications, you will find that redistributing responsibilities is fundamental to designing your internal communications approach (Lutgen-Sandvik, 2010).

\subsubsection{Know Who You're Talking to}

Once you've tapped into a dynamic team made up people from different parts of the organization and have clearly defined their roles in successfully communicating the organizational change, you need to turn your attention to your audiences. While your audience may be made up entirely of internal staff, there are likely many subsets of that group based on things such as demographics, culture, location, organizational level, function, etc. All of these characteristics affect how people will understand and be affected by change, as well as how they take in the information they are given and how they will respond. By understanding the various profiles of your audience, you can address issues such as where people fit into the change, how/if their roles will change, and how they will be supported during the change. To be sure your messages will resonate, choose a few representatives to review and provide feedback before sending these messages to a broader audience (Lutgen-Sandvik, 2010).

\subsubsection{Keep It Real}

Another pitfall for many organizations is overcomplicating the message and overwhelming the audience. Keep it short-net out the key messages so your audience doesn't have to work hard to understand the bottom line. If the change initiative is complex in nature, stage and break up the flow into bite-sized pieces that are less likely to obfuscate and frustrate. Use imagery, employ good storytelling techniques, and illustrate metrics, where possible, to help audiences grasp the key concepts and make it easier for the variety of people delivering the messaging to do so in a consistent way (Lutgen-Sandvik, 2010).

\subsubsection{Pay Attention to Timing}

Far too many organizations engage and communicate with employees too late-essentially waiting until the changes they're proposing are essentially a fait accompli. Failing to bring all your stakeholders to the table from the very beginning opens the door for a lot of misunderstanding and, in the absence of information, the making up of inaccurate stories (Lutgen-Sandvik, 2010).

\subsection{Empirical Review}

Communication covers all activities that an individual does when he wants to make a transformation in someone else's mind. This is a meaning bridge between an individual or individuals and organization. Communication is a process that contains expressing, listening and understanding (Banerji and Dayal, 2005). Similarly, emphasizing social aspect of communication, communication that takes part on the base of social life and forms the content of organizational structure is a process which aims at conducting good relationships between groups and organizations (Dogan, 2005). Ayatse (2005) observed that communication is needed to establish and disseminate the goals of the enterprise. This is because the competencies and skills they possess will enable them to exhibit work behaviours appropriate and relevant to the performance of the job. It is further theorized that employees are likely to be more productive if their performance is rewarded assuming that the reward received has value to them, as argued by the expectancy theory (Victor Vroom, 1964). Goris et al. (2000) and Ooi et al. (2006) find organizational communication to have an important positive association with affective commitment, whilst (Brunetto and Farr-Whartons, 2004) findings 'suggest a strong relationship between communication processes and job satisfaction and affective job commitment'. The importance of communication may appear intuitively obvious, but does research support this assumed importance; the short answer is yes. Research has shown that 'when employee needs are met through satisfying communication, employees are more likely to build effective work relationships.' (Gray \& Laidlow 2004, quoted in Tsai and Chuang 2009).

Rajhans (2012) opined in a study' effective organizational communication : a key to employee motivation and performance' that organizational communication plays a vital role in employee motivation and performance as real changes are taking place in modern organizations which confront the new reality of tighter staffing, increased workloads, longer hours and a greater emphasis on performance, risk-taking and flexibility. Oyetunde \& Oladejo (2012) in a study titled 'communication approach and firms' performance: appraisal of Nigerian Bottling Company (Coca-Cola), IlorinNigeria' submitted that research findings no doubt have validated the synerginous relationship between communication approach and efficient performance of NBC, Ilorin plant.

\subsection{Theoretical Framework}

In this study, the researchers' theoretical framework was built on 'The Cybernetics theory' propounded by W. Ross Ashby and Norbert Wiener in 1960 emphasized on mathematics theory of communication and control systems through regulatory feedback. Feedback can be positive (when the required result is achieved) or negative; instantaneous (when the response is immediate) or delayed. Feedback is used to gauge the effectiveness of a particular message put forth 
or situation that has taken place. Cybernetics is the study of the communication and control of regulatory feedback both in living and lifeless systems (organisms, organizations, machines), and in combinations of those. Its focus is how anything (digital, mechanical or biological) controls its behavior, processes information, reacts to information and changes or can be changed to better accomplish those three primary tasks.

In applying these theories to the subject of study it is evident that effective communication and organizational performance in UNIZIK is not just dependent on the communication flow in the various Faculties and Departments in UNIZIK. There are fourteen Faculties in the University made up of academic and non-academics. The management should not be satisfied with giving instructions, sending text messages, calling for meeting, writing memos and circulars. There is a need to personally inform staff of new policies and innovations in the university system to enable members of staff to be aware and participate effectively in issues that concern them. This is backed up with The Berlo's (1960) SMCR model which focuses on the individual characteristics of communication and stresses the role of the relationship between the source and the receiver as an important variable in the communication process. Hence the source of any information in the Faculty should be clear and from a trusted and creditable 'source' i.e. the HOD or The Dean. Likewise, the channel used should be adequate. Hence, they should know when to apply formal or informal mode of communication, since their main objective is to achieve results from staff.

Furthermore, in applying The Cybernetics theory' it becomes useful for any organization that intends to achieve employee performance to ensure that feedback mechanism should be enough either in the attitude to work, productivity, and high performance of both staff's and students of the University. Conclusively, the Vice Chancellor, The Dean, Heads of Departments ought to communicate and interact effectively, so as to become more productive in the university as a whole. Since is the outcome of the communication can either positive or negative?

\section{Methodology}

The concept of research designs has been viewed by different authors at different places, at different time and from different field of specialization. Research design is a plan, structure and strategy of the study in view of which the researcher is able to obtain the required answers to the research questions (Adefina 2008). The researcher adopted the use of non-experimental design with specification to descriptive research design: Descriptive research: This is a more indepth research that answered the question what and how. This study was carried out in Adamawa State University, Mubi. The population comprises both Academic and non-Academic Staff of Adamawa State University Mubi. The total population of the study is eight hundred and twenty-four (824) which comprises of two hundred and thirty-two Academic Staff (232) and five hundred and ninety-two (592) non academic Staff of different carders. In determination of the sample size, the researcher adopted the use of Yamani (1964).

$\begin{array}{ll}\mathrm{n}= & \mathrm{N} \\ \mathrm{N} & = \\ \mathrm{n} & =\frac{824}{1+\mathrm{N}(\mathrm{e})^{2}} \\ \mathrm{n} & =\frac{824(0.05)^{2}}{1+824(0.0025)} \\ & =\frac{824}{3.06} \\ & =\end{array}$

The study used the use of questionnaire as one of tools for collecting data. Questionnaire is a research instrument consisting of a series of questions and other prompt for the purpose of gathering information from respondents. Closed ended questionnaire is the major instrument for data collection in this study; this is because questionnaire has the capacity of collecting more relevant data from respondents. Other sources from secondary were equally utilised from textbooks, journals, website document and articles. The questionnaire was design on five points likert scale ranging from strongly agree (5), Agree (4), Undecided (3) Disagree (2), Strongly disagree (1).

The data collected for this study would be presented in table form. The researcher however, used Statistical Package for Social Sciences (SPSS) and choose frequency table and percentage method in analysing the data obtained. The formula for calculating percentage is given thus: $\frac{n}{N} \times 100$, where $\mathrm{n}=$ total number of respondents from the given option in the question, while $\mathrm{N}=$ total number of respondents sampled for the study analysis. While hypotheses will be tested using Spearman correlation 0.05 level of significance.

\section{Analysis and Results}

\subsection{Hypothesis Testing}

- $\mathrm{H}_{0}$ : Communication gaps do not have any significant impact on the achievement of organizational objective in Adamawa State University, Mubi. 
- $\mathrm{H}_{1}$ : Communication gaps have significant impact on the achievement of organizational objective in Adamawa State University, Mubi.

\begin{tabular}{|c|c|c|c|}
\hline \multicolumn{3}{|c|}{ Correlations } \\
\hline \multirow{3}{*}{ CG } & Pearson Correlation & CG & 00 \\
\cline { 2 - 4 } & Sig. (2-tailed) & 1 & $.857^{* *}$ \\
\cline { 2 - 4 } & $\mathrm{N}$ & 238 & .000 \\
\hline \multirow{2}{*}{00} & Pearson Correlation & $.857^{* *}$ & 238 \\
\cline { 2 - 4 } & Sig. (2-tailed) & .000 & 1 \\
\cline { 2 - 4 } & $\mathrm{N}$ & 238 & 238 \\
\hline
\end{tabular}

Table 1: Correlations

**. Correlation is Significant at the 0.01 Level (2-Tailed)

A Pearson's correlation analysis was conducted to examine relationships between communication gap and organizational objective. The result of correlation revealed that there is positive relationship existing between variables, $r$ $=0.857<0.5$ level of significant. Therefore, we reject the null hypothesis and accept the alternate hypothesis which states communication gaps have significant impact on the achievement of organizational objective in Adamawa State University, Mubi.

\section{Summary of Findings}

The major findings of this study have been derived from the analysis and presentation of data of this study:

- The finding revealed that poor directives by management causes confusion among employees, communication gap can also influence reduction in information flow between management and subordinates' staff, the information provided by the university management are not enough. Also, there is always opposition when opinion of all concerned are not sought in the management meeting before any decision taken. The finding also revealed that unclear responsibilities lead to poor employee performance.

- Furthermore, the finding also revealed that poor listening skill have caused negative effect on organizational objective, i.e. information pasted on the notice board may not get to all concerned employees in the organization, feedbacks are not required from all that is concerned when information or instruction are distributed. Also, ineffective interaction becomes a blockade to organizational success and when top management instructions get too wordy, organization real message may be lost.

- From the above analysis, it also revealed that management are informed of organizational goals, performance of feedback is provided in such a way that it helps staff to carry out organizational objectives, clear goals are set for the performance of employee in the organization. The finding further revealed that when management recognized the efforts of employees they tend to put in their best jobs towards organizational objectives. Also, improving internal communications flows can help organization to achieve its objectives.

\section{Conclusion and Recommendations}

This research has provided an insight into the impact of communication gaps in the achievement of organizational objectives; the hypothesis established that communication gaps have significant impact on the achievement of organizational objective. The study further concludes that poor directives given by management causes confusion among employees, communication gap can also influence reduction in information flow between management and subordinates staff, the information provided by the university management are not enough. There is always opposition among employee of ADSU when opinion of all concerned are not sought in the management meeting before any decision taken, also unclear responsibilities has led to poor employee performance in the institution.

More so, it further concludes that poor listening skill has causes negative effect on organizational objective, i.e. sometimes information pasted on the notice board may not get to all concerned employees in the institution, feedbacks are not required from all that is concerned when information or instruction are passed. Meanwhile, ineffective interaction among staff of the institution becomes a blockade to organizational success and when top management instructions get too wordy, organization real message may be lost.

The study further concludes that despites the problems encourage through communication gaps the management are informed of organizational goals, also the performance of feedback is provided in such a way that it can help staff to carry out organizational objectives diligently, clear goals are set for the performance of employee in the organization. It also observed that when management recognized the efforts of their employees they tend to put in their best towards organizational objectives. Also, improving internal communications flows can help organization to achieve its objectives. From the above findings and conclusion, the study further recommends that;

- The management of ADSU Mubi should make clear communication in order to make directive as easier as possible to employees in order to avoid confusion among employees in discharging their duties, there is also need for good flow of information between the management and their subordinates in the institution, it also good for the management to put in cognizance the interest of the organization as well as all staff as a whole in every decision making in the institution.

- The management of the institution should develop a strategy that will help them improve the listening skills of their staff for easy understanding of the organizational goals and objectives, the management should also require 
feedback from all the department in order to monitor or appraise the performance of her employees. It recommends that any importance information that will lead to the success of the institution should be shared effectively among all the staff concern.

- The management should put more emphasis and put in place strategies that will help employees to meet up with the organizational goals and objectives through effective feedback mechanism, i.e. Clear goals should be set for employees to act upon towards achieving targeted objectives. It further recommends that the management should always recognize every little contribution made by employees to ensure goals and objectives are achieve within the stipulated time, this will go a long way in improving internal communications flows among employees.

\section{References}

i. Ayatse, F. A. (2005). Management information system: A global perspective. Makurdi: Oracle.

ii. Banerji, A. \& Dayal, A. (2005). 'A Study of Communication in Emergency Situations in Hospitals', Journal of Organizational Culture, Communications and Conflict 9(2), 35-45.

iii. Banihashemi, S. A. (2011). The Role of Communication to Improve Organizational Process. European Journal of Humanities and Social Sciences1(1), 13-24.

iv. Bass, B. M. (1985). Leadership \& Performance Beyond Expectations. New York, NY: Free Press.

v. Brun, O. C. \& Summers, J. (2010). Business Ethics: Ethical Decision Making and Cases. Boston: Houghton Mifflin.

vi. Brunetto, Y. \& Farr-Wharton, R. (2004). Does the Talk Affect Your Decision to Walk, Management Decision, 42, 579-600?

vii. Chen, Ni. (2008). 'Internal/Employee Communication and Organizational Effectiveness: a study of Chinese corporations in transition.' Journal of Contemporary China 17 (54) 167-189.

viii. Cheng, M. I., Dainty, A. R. J. \& Moore, D. R. (2005). 'What makes a good project manager?', Human Resource Management Journal, 15(1): 25-37.

ix. Cheryl, H. (2013). Communicating for Results: A Guide for Business and the Professions Interscience. Management Review (IMR). 2, (2). 1513-2231.

x. Chudi-Oji, C. (2013). Behaviour Organization and Managing the Human Side of Work. Allyn and Bacon Inc; New york, 92-98.

xi. Dogan, S. (2005). Çalısan_liskileri Yönetimi, Kare Yayınları,_stanbul.

xii. Downs, C. W. \& Hazen, M. D. (1977). A factor analytic study of communication satisfaction. Journal of Business Communication, 14(3), 63-74.

xiii. Emuze, F. \& James, M. (2013). 'Exploring communication challenges due to language and cultural diversity on South African construction sites', Acta Structilia, 20(1), 44-65.

xiv. Eresimadu, K. (2003). Educational Management Theory and Practice, Enugu Jamoe Enterprises Nigeria.

xv. Ferkins, L. \& Shilbury, D. (2010). Developing board Strategic Capability in Sport Organisations: The National Regional Governing Relationship. Sport Management Review, 13, 235- 254.

xvi. Ferkins, L., Shilbury, D., \& McDonald, G. (2009). Board involvement in strategy: Advancing the governance of sport organisations. Journal of Sport Management, 23, 245-277.

xvii. Goris, J. R., Vaught, B.C. \& Pettit, J. D. (2000). Effects of communication direction on job performance and satisfaction: A moderated regression analysis, Journal of Business Communication, 37(4), 348-68.

xviii. Gray, J. \& Laidlaw, H. (2002). Part-time employment and communication satisfaction in an Australian retail organization. Employee Relations. 24 (2), 211-228.

xix. Hassan, M., Mukhtar, A., Qureshi, S. U. \& Sharif, S. (2012). Impact of TQM Practices on Firm's Performance of Pakistan's Manufacturing Organizations. International Journal of Academic Research in Business and Social Sciences. 2(10) 232-259.

xx. Koontz, E. (2001). Making theory Operational, journal of Management Studies, 3, (3), 229-43.

xxi. Lutgen-Sandoik, J. M. (2010). The cultures of work organisations Englewood cliffs. New Jersey: Prentice-Hall.

xxii. Mangal, S.K \& Mangal, U. (2009). Essentials of Educational Technology. New Delhi: PHI Learning Private Ltd.

xxiii. McGraw-Hill, (2001). Defining Communication. Theories. New York: McGraw-Hill Higher Education. The McGrawHill Companies.

xxiv. Mckinney, E. H., Barker, J. R., Smith, D. R. \& Davis, K. J. (2004). The role of communication values in swift starting action Teams: IT insights from flight crew experience, Journal of Information \& ManagementManagement. 41(8), 1043-1056.

xxv. Miller, K. (2009). Organizational communication. Belmont, CA: Thomson Wadsworth.

xxvi. Obamiro, J. K. (2011). Management Principles \& Strategies, Lagos: Pumak Nigeria Limited.

xxvii. Ooi, K. B, Safa, M. S. \& Arumugam, V. (2006). TQM Practices and Affective Commitment: A Case of Malaysian semiconductor Packaging Organizations, International Journal of Management and Entrepreneurship, 2(1), 37-55.

xxviii. Oyetunde, 0. \& Oladejo, M. (2012). Communication Approach and Firms Performance: Appraisal of Nigerian Bottling Company (Coca cola), Ilorin-Nigeria. Research on Humanities and Social Sciences,2 (1):14-24.

xxix. Richmond, V. P. \& McCroskey, J. C. (2009). Organizational Communication for Survival: Making work (4th ed), Boston, MA: Allyn and Bacon.

xxx. Shilbury, D., Ferkins, L., \& Smythe, L. (2013). Sport Governance Encounters: Insights from lived experiences. Sport Management Review, 16, 349-363.

xxxi. Stephen, C. (2011). Research methodology in Business and social sciences, Owerri Canon. 
xxxii. Tsai, M. T. \& Shuang-Shii, C. (2009). An Integrated Process Model of Communication Satisfaction and Organizational Outcomes. Social Behavior and Personality 37 (6).

xxxiii. Williams, C. (2007). Management $4^{\text {th }}$ edition. USA: Thomas Higher Education. 